\title{
Obituary
}

\section{Dr. Abdul Qadeer Siddiqui}

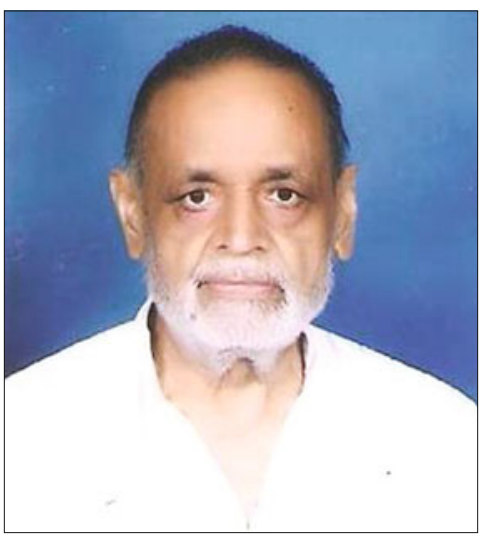

Dr. Abdul Qadeer Siddiqui

Dr. Abdul Qadeer Siddiqui passed his MBBS from KGMC, Lucknow in 1958 and subsequently joined Central Institute of Orthopedics at Safdarjang Hospital, New Delhi. Working under Prof. P. K. Duraiswami, he obtained MS (Ortho) degree from University of Delhi. He joined Uttar Pradesh Government medical services. He worked as an orthopedic surgeon in Uttar Pradesh Government hospitals at Fatehpur, Azamgarh, Varanasi and Allahabad. He earned a reputation as an efficient orthopedic surgeon with empathy towards the needy people. Some of his last assignments were chief medical officer of Azamgarh and Fatehpur, chief medical superintendent of T B Sapru Hospital at Allahabad and additional director of U.P. medical services. He retired from government job in 1998 and settled in Allahabad. He developed a successful orthopedic practice and earned the goodwill of the society wherever he worked.

He was a life member of Indian Orthopedic Association and attended most of the conferences regularly. He was professionally and socially active almost up to the last phase of his life. He passed away peacefully on $12^{\text {th }}$ September 2013. He is survived by his wife and three sons who are settled abroad.

AN Varma

Ex-Professor \& Head, Department of Orthopedics, Motilal Nehru Medical College, Allahabad, Uttar Pradesh, India E-mail:varmaan@rediffmail.com

\begin{tabular}{|l|l|}
\hline \multicolumn{2}{|c|}{ Access this article online } \\
\hline Quick Response Code: & \\
\hline & \\
\hline
\end{tabular}

